\title{
Political Affairs Supermarket-Orientation of Transformation of Government Management
}

\section{Yongsheng Li}

\author{
Department of Management Science, Weinan Normal University, Weinan 714000, China
}

Keywords: Political Affairs Supermarket; Government; Management

\begin{abstract}
Since the first political affairs supermarket has been set up in Nanjing, political affairs supermarket has spread everywhere and it has become the major way of government. With reforming further, government should focus on perfecting political affairs supermarket in next decades to promote its development objectives.
\end{abstract}

\section{The Origin of Government Supermarkets}

The term "political affairs supermarket" refers to the government's implementation of public services in the mode of commercial operation and operation and management. It emphasizes that the government streamlines procedures, improves handling procedures, and exchanges and improves service quality in the process of providing public services and improving management methods to provide the public with convenient and efficient office space, to optimize various service work with new ideas, new procedures and new methods so as to achieve the purpose of reducing administrative costs, improving administrative efficiency and enhancing public satisfaction [1]. This is not only a change of government functions important forms, but also the performance of government services innovation.

Government supermarkets, which date back to the early 1980s as Western government reforms, focus on the cost and efficiency of government operations and streamline institutions and personnel through competitive orientation, customer orientation, service orientation and results orientation. The new public administration movement that started in the 1990s further set off a large-scale reform of the government. The goal of government reform is to introduce the successful management experience and methods of enterprises so as to change the focus of government work and effectively provide public goods and services with the least investment obtained the maximum output, for the emergence of government supermarkets to provide a theoretical and practical basis [2].

With the deepening of the government reform in our country, on October 16, 2000, the Xiaguan District CPC Committee and the district government of Nanjing introduced a new form of administrative service in the small streets of the area and the two streets of the Rehe Nanan Road, that is, the civil service, employment, urban construction , The administrative functions of more than 40 service items in eight major categories such as economy, letters and visits, law and administration are centralized in a hall or several windows. This open and transparent form has the characteristics of selectivity, convenience and diversity, similar to the "supermarket", so it is vividly called the government supermarkets. This is a new form that appears in the process of deepening the reform of the administrative system in our country. With the increase of people's diversified needs, various government departments such as "Re-employment Supermarket for Laid-off Workers", "Migrant Workers Supermarket", "Administrative Service Center", "Administrative Examination and Approval Service Center" and "Administrative Service Center" The form of supermarkets has played an important role in helping the people to do practical work [3].

Government supermarkets not only focus on the formal changes of departments and departments in a window or departmental joint office, but the key point is to take the principle of "solving problems for the people and meeting the needs of the people" and saving time. Strengthen the communication between the government and the people, change the administrative system that does not meet the needs of the market economy, inject new vitality into the restructuring and reform of 
the government agencies, unite the various functional departments of the government and set up platforms for various departments to communicate and cooperate, and transform the government Working style not only facilitates people but also improves efficiency. Therefore, this form marks the beginning of the internationalization of our country's administration and embodies the alignment of our country's administrative system with that of the rest of the world.

\section{The Significance of Building Government Supermarkets}

The development of market economy requires our government to change from single governance and multiple governance, emphasize the cooperative governance between the government and non-governmental organizations, state and society, public and private sectors. The government supermarkets are of great significance in improving and compensating the defects of government governance.

\subsection{Open government information.}

The most prominent feature of government-run supermarkets is that they open government service procedures and service projects and realize the leap from "red tape" to "one-stop", which reflects the principle of "helping the people, facilitating the people and benefiting the people". Promoting the communication between the government and the people through open government affairs information has enhanced the feelings of the government and the people, helped the people to supervise the government's work and to a certain extent curbed the breeding of corruption, transformed the rigid government work style and the numerous Approval process, improve government performance.

\subsection{Change the government functions}

Improve the level of government governance requires the effective transformation of government functions so that the government can play an effective role in the management of public affairs. The government supermarkets are important for the government to set up one or more departments and windows to handle all the affairs required by the people and merge many tasks Move. With the transfer of the current work focus and the increase of the work content, the operation of the government-run supermarkets has realized the transformation of government functions while improving the efficiency of government work, and has reflected the innovation of government functions.

\subsection{Improve the ability of civil servants}

Government supermarkets require civil servants of government agencies to change the status quo of doing things harshly and irresponsibly, improving the efficiency and sense of service of civil servants, prompting civil servants to clarify the significance of constructing government supermarkets, shifting the concept of job performance to their daily work, implementing " Do a limited time to do "one-stop service, improve its efficiency and service levels, enhance the image of the government and better serve the people.

\subsection{Strengthen the cooperation of all government departments}

Government supermarkets follow the service mode of "Joint Office, Office of Reply, Office of Solution, Office of Consolation", merging the work of dozens of departments such as business administration, taxation, finance, and economic planning commissions to break the barriers between departments and form a networked, Seamless service system, so that different departments in the same place at the same time to work at the same time, to solve the "door intolerable, difficult to see, face ugly, difficult to do things" Yamen-style work to avoid pushing each other and wrangling Drawbacks, cater to the government department reform.

\subsection{In line with Chinese service-oriented government needs}

The report of the 17th National Congress of the Communist Party of China pointed out that the 
direction of the administrative system reform is to build a service-oriented government. With the development of society and the improvement of people's awareness of participating in politics, people's demand has increased, requiring the government to provide high-quality public services to the people with service orientation. Government supermarkets have realized the convenient and quick service mode, abandoned the traditional bureaucratic monopoly and coercive features, promoted the government's transition from regulation to service, reflected the modern democratic administrative spirit of "taking the people as the foundation" and "serving the people as the people" For the political, economic, cultural and social aspects of providing a good service environment [4].

\subsection{Speed up the development of e-government in our country}

Government supermarkets advocate convenient and efficient service, enhance the modern quality of government public service, form the interaction between government, people and society, and optimize the "interface" between government and clients. With the development of informatization and networked society, the communication network platform set up between government and society also urges the government to open the portal website in an all-round way, set up a democratic mail box, carry out public opinion polls regularly, improve working methods and service contents according to the investigation conditions, Information exchange, resource sharing and interoperability [2].

In short, the government supermarkets optimize the government internal business processes and external service processes, simplifying procedures, improving service quality and realizing long-distance operations to "one-stop" services, in line with Chinese administrative management system reform and the transformation of government functions.

\section{The Development of Government Affairs Supermarkets}

Although government supermarkets have made remarkable achievements in regulating government governance, improving work efficiency and promoting government image, the construction of government supermarkets in our country is short and the corresponding mechanism is not perfect. The main problems are as follows:

\subsection{Concept of perspective narrow.}

As the concept is not in place, some local governments do not know the full implementation of the government supermarkets, operating environment and job restructuring, and do not reflect the achievements and experiences in the construction of government supermarkets theoretically, nor do they conscientiously sum up and analyze the supervisors' of the understanding is only on the superficial level of disciplinary discipline and work style improvement. Some civil servants even suspect the role and effect of the construction of government supermarkets, which may be just formal changes. Such a narrow concept makes the full implementation of government supermarkets more A long time can completely change the government's rigid procedures.

\subsection{Services coverage is narrow}

At present, the one-style services embodied in government supermarkets cover only nine categories of social security, civil affairs, city appearance management, employment services, reception of letters and visits, administration of business consulting, tax collection, comprehensive services and deputies to the people's congress, while the broader public service It is not fully integrated into the service areas of government supermarkets and cannot meet the public's public needs in a wider area. In addition, government supermarkets really play a central role in big cities. However, the construction of government supermarkets in small and medium-sized cities or at subordinate levels is slow or just superficial and formalistic, which also limits the service scope of government supermarkets.

\subsection{Government window is not powerful}

Although the form of government supermarkets require that all work be concentrated on 
consultation in one window or department, the authority of the government window only relates to the daily reception, and the signature and stamping only serves as a simple "mailroom". However, certain major affairs or The urgency to handle the issue only to play the role of "urged to handle" without administrative examination and approval of the final decision still need to ask the higher authorities to handle, indicating that the government has not fully delegated these areas, limiting the size of the development of government supermarkets.

\subsection{The degree of legal system is not high}

Currently, the government supermarkets also lack the relevant laws and regulations, the legal system is a long way to go, is not conducive to improving the operating mechanism and level of government supermarkets, it is difficult to consolidate the experience and achievements in the development of government supermarkets, resulting in government affairs staff No relevant laws and regulations can be followed, the work cannot be carried out according to the principle of law, and some issues such as subjective assumptions and arbitrary sloppyness have all become issues that the government supermarkets should expect to improve.

\section{The Path to Improve the Choice of Government Supermarkets}

To change the functions of government, promote the reform of government agencies, create a mechanism of competition and innovation, and strive to improve the standard of government staff, we should further improve the government supermarkets as the direction of government governance from the following aspects.

\subsection{Locate the role of government and actively change their functions}

The development of market economy has a profound impact on government behavior. The government must change its traditional central position and establish a service orientation mechanism to provide relevant services for the development of all areas in the region. To this end, the government should play its role in coordinating social order, supervising the market and promoting the macroeconomic development so as to shift from direct control and intervention to indirect regulation and service. The focus of the reform is to be streamlined in a scientific, rational, open and efficient manner Organizations, redundancy elimination, comprehensive clean-up and substantial reduction of administrative procedures and the full decentralization of power, change the power to serve greatly improve the efficiency of government supermarkets.

\subsection{Reform the government system and innovate the government mechanism}

In order to adapt to the reality of economic globalization and rapid social changes, the government should give full play to the active role of government supermarkets, reshape the government agencies with a flexible, flat and flexible organizational structure, and reform the governance system and bureaucratic structure to reduce Delay and inefficiency caused by the expansion of the middle executive layer, shorten the time and improve efficiency, provide people with convenient and efficient service and enhance the government's ability to cope with social changes, and on this basis, innovate the operation mechanism of the government and persist in the lead with innovation as the turning point Ask the responsibility system, the public commitment system and the supervisory feedback system to drive the development of various affairs so that the government supermarkets can play a role in all government departments and sectors and improve the operational efficiency of government supermarkets.

\subsection{Implementation of departmental responsibilities, increase service content}

Therefore, the service of the government supermarket window should embody the functions of "one-stop office", "one-stop service", "service in the sunshine" and "service in the sun" Standardized operation "principle of work to further implement the responsibilities of various departments. With the complex and diverse needs of the people, the government should include the people's livelihood issues such as social security, education and employment, health care, social 
welfare, environmental protection and public infrastructure, which are generally concerned by the people, in the service items of the government supermarkets, set up talk-heart clinics and legal advice, Street leadership information, direct telephone, leading reception days and other services, and in accordance with the needs of the people promptly update the service content.

\subsection{Deepen personnel reform and improve working ability}

The quality and ability of the government staff directly determines the operation level of government supermarkets. Therefore, on the basis of deepening the personnel reform, a staffing mechanism of open choice, competition in employment, and "under the able, flat, under the mediocre" Regularly check the government affairs staff, regard the service attitude, work efficiency and innovation ability as the standard assessment staff, supervise the staff to improve their quality, firmly establish the concept of "serving the people" and the awareness of "public servant", and improve the system of complaints pending posts , Non-compliance system, supervision and feedback system, performance appraisal system, and accountability system. Through education and training, the concept of service enjoys popular support, ensuring that every civil servant is conscientious and responsible and dares to accept the supervision and evaluation of the people.

\subsection{Cultivate social organizations, build government supermarkets}

Social organizations play a positive role in providing public services, meeting the needs of the people and coordinating the relations between the government and society. It is necessary to give full play to social organizations in order to achieve the goal of building government supermarkets. Encourage intermediaries and private enterprises to participate in the construction of government supermarkets and realize the governance model of "weak government and strong society". Through outsourcing, privatization and reform, as well as contracts and entrustment, the government fosters a partnership of sharing responsibilities and interests with social organizations and forms a collaborative governance of government and social organizations to build a government-led supermarket.

\subsection{Pay attention to service efficiency, improve e-government}

Make full use of information technology to build a platform for online communication between the government and the people, fully open government portals and conduct online work and operations in an open and transparent manner. Further realize the integration and sharing of information resources, rationally layout the LAN, and realize the information sharing among the provincial, upper and lower levels and departments [6]. Expand service space, improve the efficiency of government supermarkets. Research and development of software systems suitable for the service contents of government supermarkets and accelerate the construction of "online virtual municipal government service centers". Use network construction for policy advocacy, departmental business presentation, information bulletins, data inquiries and other one-way service or transmission of information to answer questions of people, online reporting, online licensing, online annual inspection, e-mail, online opinion polls, online complaints, problem handling Feedback and other two-way service to improve the efficiency of government supermarkets.

With the transformation of government governance, government service supermarkets should be the direction of government governance transformation and expansion of service content and space in order to improve the efficiency of government governance and achieve the goal of government reform.

\section{Acknowledgements}

Fund Project: This article is a research project of Weinan Teachers College, project number: 08YKZ014 


\section{References}

[1] Chen Hu, Wu Yan. "Government supermarkets": a new model of government public administration in the new era [J]. Party and government cadres Forum .2004 (4): 28

[2] Wang Jiajie. Government supermarkets: to create a local service-oriented government [J]. Consumption Guide .2007 (4): 221

[3] Liu Jing, Chen Hu. Government supermarkets: a remodeling of a local government movement [J] .2004 (7): 51

[4] Zhang Jianzhong. "Government supermarket" quietly into the middle of the people [J]. Price and market .2002 (1): 19-20

[5] Li Jinlong Executive Board: progressive development of government supermarkets trend [J]. Chinese Administration .2007 (6): 42-43

[6] Xie Qingkui, Tong Fu Ling. Service-oriented government and harmonious society [M]. Beijing: Peking University Press, 2006: 42-44 